Revista Signos

$2010 / 43$

Número Especial

Monográfico $\mathrm{N}^{\circ} 2$

\section{Editorial \\ El poder de los actos comunicativos en el análisis de las desigualdades y las posibilidades de transformación social}

Desde la Agenda de Lisboa del año 2000 hasta la actual Estrategia Europa 2020, la Unión Europea sigue trabajando por uno de sus mayores retos, la cohesión social, en un conglomerado de 'todavía estados nación' con historias, culturas y lenguas de todo el mundo, más intereses y particularidades regionales y nacionales. En consonancia con este reto, el año 2010 se declara Año Europeo contra la Pobreza y la Exclusión social ya que, golpeado por la crisis económica, el supuesto gigante europeo debe afrontar nuevas desigualdades sociales y de derechos que se han generado entre una ciudadanía cada vez más plural. Entre diferentes eventos organizados, el congreso "La Ciencia Contra la Pobreza" se ha centrado en la aportación de la ciencia y la innovación a la lucha contra la pobreza y la exclusión. Es precisamente en este punto, donde las ciencias sociales tienen una importante tarea desde la investigación y la definición de soluciones que contribuyan a disminuir los altos índices de pobreza (actualmente, en Europa, hay 85 millones de personas pobres, de estas, 19 millones son niños y niñas) y el riesgo de exclusión social. Erik O. Wright, actual presidente de la Asociación Americana de Sociología, plantea hoy la necesidad de unas ciencias sociales emancipadoras, que incluyan una parte de diagnosis y crítica, otra de análisis de alternativas y otra de elaboración teórica hacia una teoría de la transformación.

En esta línea, el monográfico que aquí se presenta se centra en análisis elaborados en el marco del proyecto INCLUD-ED, el único proyecto integrado en socio-economía coordinado desde España en el Programa Marco de Investigación de la Unión Europea. INCLUD-ED se dirige desde el CREA, Centro de Investigación en Superación de Desigualdades de la Universidad de Barcelona. Este proyecto, que coordina quince equipos de investigación de catorce países europeos, investiga actuaciones educativas de éxito para la inclusión social y su efecto en el empleo, la vivienda, la salud y la participación política. 0 sea, analiza aquellas estrategias que demuestran funcionar en centros educativos, barrios y ciudades para superar la exclusión social en ese 
entorno. El objetivo principal es identificar elementos normativos comunes en esas acciones, de forma que puedan ser transferibles a cualquier contexto europeo o mundial y orientar el diseño de políticas en Europa que contribuyan a la transformación social.

Una dimensión clave de este estudio es el análisis de las relaciones humanas a través del lenguaje. Conocer la naturaleza de las interacciones que se generan entre profesorado, alumnado y familiares de una escuela que se basa en una organización democrática o jerárquica es clave para diferenciar cuándo y cómo se reproducen o se superan las desigualdades. Las relaciones entre el jefe de una planta de producción y sus empleados y empleadas pueden ser muy diferentes si el contexto de trabajo fomenta interacciones igualitarias y sinceras o por el contrario facilita el acoso y la imposición. El proyecto INCLUD-ED introduce el análisis de actos comunicativos dialógicos y de poder en diferentes contextos de acción.

Los actos comunicativos introducen elementos del análisis de la acción social a la teoría de los actos de habla. En debate con John Searle, los investigadores del CREA plantean la necesidad de encontrar una unidad de análisis más amplia para diferenciar, por ejemplo, cuando en una relación existe libertad o acoso sexual, igualdad de trato o discriminación étnica. El concepto de 'acto comunicativo' (Searle \& Soler, 2004) incluye la preocupación de Habermas por identificar, en el uso del lenguaje, pretensiones de validez y de poder, pero va más allá del autor alemán: no nos centramos en las intenciones (de verdad o imposición) de cada sujeto hablante, sino además de esas intenciones en aquellas interacciones que también genera la situación de ese hablante en la estructura social. Aunque un jefe sea muy amigo de su empleada, existe una interacción de poder fruto de la jerarquía de las relaciones laborales. Los actos comunicativos además incluyen tanto el habla como el lenguaje simbólico no verbal al analizar hasta qué punto las relaciones humanas que se generan en un contexto educativo un proyecto social o una empresa son dialógicas o de poder.

Pensamos que este tipo de análisis son cada vez más necesarios en un mundo globalizado donde aumenta la posibilidad de diálogo entre géneros, culturas, etnias y religiones, a la vez que se polarizan las desigualdades sociales y aumenta la violencia y la pobreza en barrios vecinos al discurso de la paz y a la riqueza. El estudio de los actos de habla y actos comunicativos en contextos reales de interacción humana está hoy realizando aportaciones clave a la investigación y teorización, en palabras de Wright, de alternativas sociales viables para el empoderamiento y la transformación social.

Desde este contexto académico y profesional, Revista Signos. Estudios de Lingüística ha programado este segundo número monográfico del año 2010 con el propósito de contribuir a los objetivos de INCLUD-ED y del CREA y, del mismo modo, manteniendo viva su misión, cual es 
estimular y facilitar el intercambio académico entre investigadores de la comunidad científica internacional. Para ello, se cuenta con el apoyo ecónomico del Fondo de Publicaciones para Revistas Científicas del Consejo de Ciencia y Tecnología de Chile (CONICYT), a través del proyecto ganado para este año 2010.

Este número monógrafico se ha constituido con siete trabajos científicos los cuales han seguido las normas regulares de publicación en nuestra revista, esto es, evaluación por medio de pares expertos anónimos. Los siete artículos se organizan en torno a una temática específica como es el estudio de los actos de habla.

Esperamos muy sinceramente que este número de Revista Signos. Estudios de Lingüística se constituya en un medio de interacción entre las comunidades académicas y profesionales y, por medio del desarrollo científico, se logre así apoyar el trabajo en torno a la ayudar a superación de algunos de los magros indicadores de pobreza en el mundo.

Giovanni Parodi

Marta Soler

Editores

Número Especial Monográfico $\mathrm{N}^{\circ} 2$ 